\title{
Estimation of left ventricular size by echocardiography
}

\author{
D. G. Gibson ${ }^{1}$ \\ From the Department of Cardiology, St. Bartholomew's Hospital, London
}

A comparison of echocardiography with angiocardiography in estimating left ventricular dimensions was undertaken in 50 patients. Angiographic data were derived from biplane Elema films, and echocardiography was used to measure the distance from the endocardial surface of the posterior wall of the left ventricle to the posterior surface of the interventricular septum. Left ventricular volume, calculated as the cube of the echocardiographic dimension, was related to that derived from angiography $(r=0.91$, standard error of the estimate $6 \mathrm{Iml}$. In 32 patients, duplicate determinations of both angiographic and echocardiographic measurements were available, allowing the experimental error of each to be estimated. In this group, the echocardiographic dimension was shown to be similar in magnitude to, but not identical with, the mean minor axis measured by angiography. Lack of fit between the two methods occurred in patients in whom left ventricular cavity shape was abnormal. There were also significant differences between the two measurements at end-systole and enddiastole, and between patients in atrial fibrillation compared with those in sinus rhythm. Comparison of residual values in the same patient between observed and predicted dimensions at end-systole and end-diastole showed a significant relation between the two.

It was concluded that the left ventricular dimension measured by echocardiography was related to the angiographic mean minor axis and also to cavity shape. The method appears particularly suitable for multiple determinations in the same patient.

Recent studies (Feigenbaum et al., 1969; Fortuin et al., 1970; Pombo, Troy, and Russell, 1971) have indicated that left ventricular volume may be estimated by echocardiography as the cube of the distance from the interventricular septum to the posterior wall. The method has considerable advantages over those currently available, since it is rapid, atraumatic, and safe, but it assumes that a comparable dimension is measured in each case, and that left ventricular shape is predictable from patient to patient.

In the present study, which was based on a comparison of the two methods in 50 patients, these assumptions were examined and the relation between the two sets of measurements investigated, in order to identify factors leading to disagreement between them.

\section{Subjects and methods}

Fifty patients undergoing diagnostic right and left heart catheterization were studied. Clinical details are given in Table I. Their ages ranged from 21 to 66 years and

Received 8 May 1972.

${ }^{1}$ Present address: Brompton Hospital, Fulham Road, London $\mathrm{SW}_{3} 6 \mathrm{HP}$.
28 were men; 24 were in sinus rhythm and the remainder were in atrial fibrillation. In 32 , duplicate determinations of angiographic and echocardiographic measurements were available, and these patients were also studied as a separate subgroup, whose composition is given in Table I.

\section{Angiographic methods}

The patients were studied supine and fasting. Five to ten mg diazepam were given intravenously, approximately 5 minutes before the angiogram, but no other premedication was used. In all patients, the angiogram from which volume measurements were made was the first to be performed in the diagnostic study. Measurements were made from anteroposterior and lateral Elema films exposed at 6 frames/sec. In 47 patients, contrast medium (Conray 420, 70\% meglumide iothalamate) was injected into the left ventricle, and in the remaining 3 patients, all with severe aortic regurgitation, into the aortic root. The dose of contrast was in the range $50-80 \mathrm{ml}$ and was given as a single injection at a flow rate of $25-40 \mathrm{ml} / \mathrm{sec}$. Exposures were timed with respect to the electrocardiogram using a solar cell (Fleming and Watson, 1967), and measurements were not made on films exposed in ectopic or postectopic beats. In 32 patients, duplicate determinations were made during 2 cardiac cycles, while in the remainder, only I cycle was adequately visualized. End- 
TABLE I Clinical data

\begin{tabular}{|c|c|c|c|c|}
\hline \multirow[t]{2}{*}{ Diagnosis } & \multirow{2}{*}{$\begin{array}{l}\text { Total No. } \\
\text { in series }\end{array}$} & \multicolumn{3}{|c|}{ No. in series with replicated data } \\
\hline & & Sinus rhythm & Atrial fibrillation & Total \\
\hline Mitral stenosis & 6 & 0 & 5 & 5 \\
\hline Mixed mitral valve disease & 12 & 0 & 4 & 4 \\
\hline Aortic valve disease & 13 & 8 & 2 & Io \\
\hline Multiple valve disease & 7 & 2 & 3 & 5 \\
\hline Nonrheumatic mitral regurgitation & 4 & 2 & 2 & 4 \\
\hline Hypertrophic obstructive cardiomyopathy & $\begin{array}{l}\mathbf{4} \\
3\end{array}$ & $\mathbf{I}$ & $\mathbf{I}$ & $\begin{array}{l}\mathbf{4} \\
2\end{array}$ \\
\hline Left ventricular aneurysm & 4 & 2 & 0 & 2 \\
\hline Alcoholic cardiomyopathy & $\mathbf{I}$ & 0 & 0 & 0 \\
\hline Total & 50 & 15 & 17 & 32 \\
\hline
\end{tabular}

diastolic films were taken as those exposed on the $\mathbf{R}$ wave and end-systolic films as those exposed on the $T$ wave of the electrocardiogram.

Ventricular volumes were calculated by the method of Arvidsson (196r). The long axes of the projections of the left ventricular cavity in the anteroposterior and lateral planes were measured after completion of the ellipse in the subaortic and mitral valve regions, and from these the true long axis of the ventricular ellipsoid was calculated. The short axes in the anteroposterior and lateral planes were measured perpendicular to the corresponding long axes, and all were taken from the midpoint of the trabeculae. It was assumed that the volumes of the subaortic space and the papillary muscles

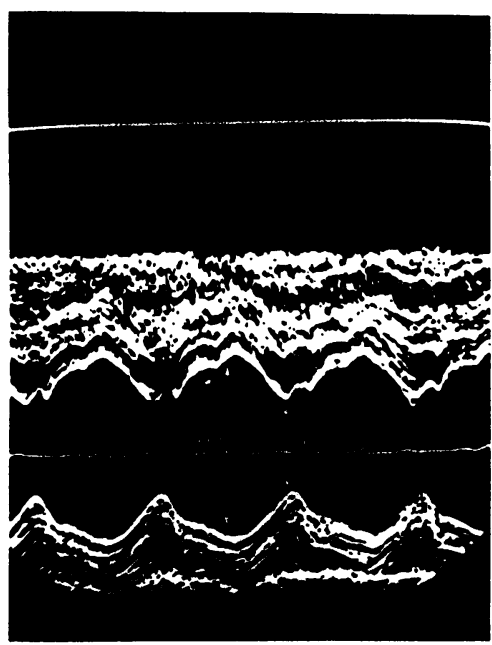

SEPTUM

ECG

POSTERIOR

WALL OF

LEFT VENTRICLE

\section{LEFT VENTRICULAR CAVITY}

FIG. I Echocardiogram showing end-diastolic ( $D d)$ and end-systolic (Ds) dimensions. were equal, and no correction was made for the volume of blood between the cusps of the mitral valve. Corrections for magnification of $I \cdot 2$ in the anteroposterior and $\mathbf{I} \cdot 3$ in the lateral plane had been previously determined, and were applied throughout, but no other correction factors were used.

\section{Echocardiographic methods}

Echocardiographic measurements were made I to 3 days before cardiac catheterization with an Ekoline 20 Ultrasonoscope, using a 2.25 $\mathrm{MHz} 0.5$ in. diameter probe with a repetition frequency of $1000 / \mathrm{sec}$ and, in all, a simultaneous electrocardiogram was recorded. The distance from the interventricular septum to the posterior wall of the left ventricle was measured by the method of Chapelle and Mensch (1969) and Popp and Harrison (I970), though no attempt was made to locate the epicardial surface of the left ventricular wall by manipulation of the damping control. With the transducer in the fourth left interspace, the characteristic echo from the anterior cusp of the mitral valve was first identified. The transducer was then angled to localize first the mitral valve ring, and then to make a record demonstrating both the interventricular septum and the posterior wall. The posterior wall was identified by its distance from the transducer and by its characteristic anterior movement during ventricular ejection. Particular care was taken to record endocardial echoes rather than those from more densely reflecting myocardium or posterior mediastinal structures. The interventricular septum was identified from its position anterior to the mitral valve ring, and in all patients it showed a posterior movement during ventricular ejection. The internal dimension of the left ventricle was taken as the distance from the posterior of the two parallel septal echoes to the endocardial surface of the posterior wall. End-diastolic measurements were made on the $R$ wave of the electrocardiogram, before the slight outward movement associated with isovolumic contraction, and end-systolic measurements were made at the time of least separation of the two echoes. Distances were assessed using the scale of centimetres superimposed on 


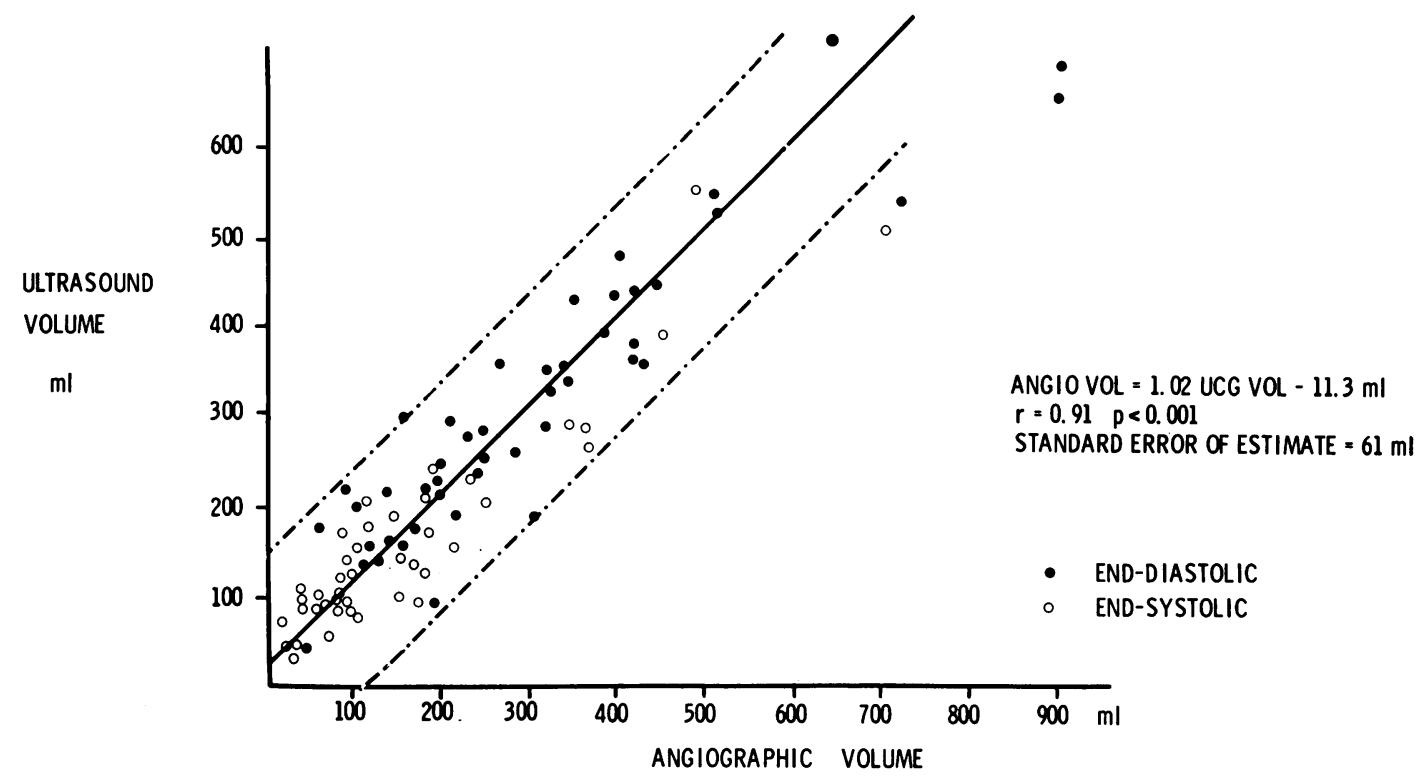

FIG. 2 Overall relation between angiographic volume and echocardiographic volume derived from the cube of the internal ventricular dimension in 50 patients. The regression line is shown with limits set at 2 standard errors of the estimate.

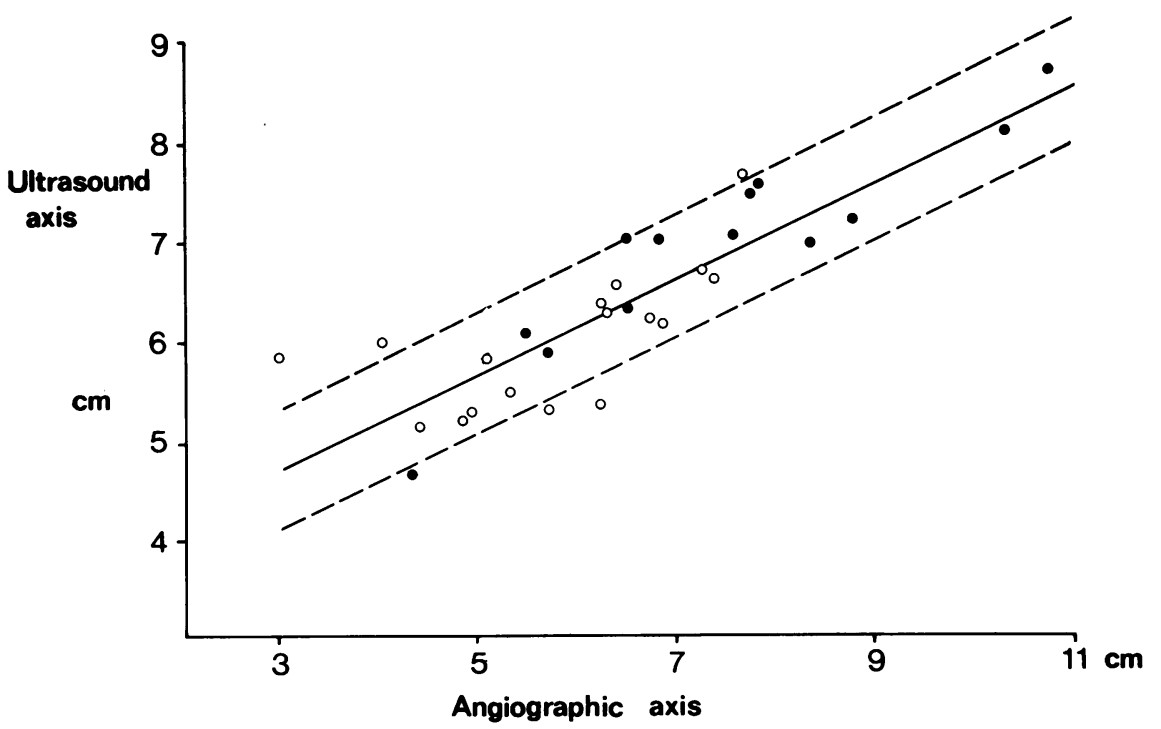

FIG. 3 Relation between end-diastolic angiographic mean minor axis and echocardiographic left ventricular dimension in 32 patients in whom duplicate determinations were available. The regression line is shown, together with the 99 per cent confidence limits.

○, sinus rhythm; $\bigcirc$, atrial fibrillation. 
TABLE 2 Summary of data from 50 patients

\begin{tabular}{|c|c|c|c|c|c|c|}
\hline $\begin{array}{l}\text { Dependent variable } \\
y\end{array}$ & $\begin{array}{l}\text { Independent variable } \\
x\end{array}$ & $\begin{array}{l}\text { Time in } \\
\text { cardiac cycle }\end{array}$ & $\begin{array}{l}\text { Slope } \\
(a)\end{array}$ & $\begin{array}{l}\text { Intercept } \\
\text { (b) }\end{array}$ & $r$ & $\begin{array}{l}P \\
<\end{array}$ \\
\hline $\begin{array}{l}\text { I) Lateral minor axis }(\mathrm{cm}) \\
\text { 2) Lateral minor axis }(\mathrm{cm}) \\
\text { 3) AP minor axis }(\mathrm{cm}) \\
\text { 4) AP minor axis }(\mathrm{cm})\end{array}$ & $\begin{array}{l}\text { Major axis } \\
\text { Major axis } \\
\text { Major axis } \\
\text { Major axis }\end{array}$ & $\begin{array}{l}\text { End-diastole } \\
\text { End-systole } \\
\text { End-diastole } \\
\text { End-systole }\end{array}$ & $\begin{array}{l}0.63 \\
0.75 \\
0.54 \\
0.66\end{array}$ & $\begin{array}{l}-I \cdot 07 \\
-3.01 \\
+0.48 \\
-I \cdot 76\end{array}$ & $\begin{array}{l}0.71 \\
0.81 \\
0.67 \\
0.79\end{array}$ & $\begin{array}{l}0.001 \\
0.001 \\
0.001 \\
0.001\end{array}$ \\
\hline $\begin{array}{l}\text { 5) Angiographic volume (ml) } \\
\text { 6) Angiographic volume (ml) }\end{array}$ & $\begin{array}{l}\text { (Mean minor axis) })^{3} \\
\left(\text { Mean minor axis) }{ }^{3}\right.\end{array}$ & $\begin{array}{l}\text { End-diastole } \\
\text { End-systole }\end{array}$ & $\begin{array}{l}0.8 \mathrm{I} \\
0.94\end{array}$ & $\begin{array}{r}+25 \cdot 4 \\
+8 \cdot 4\end{array}$ & $\begin{array}{l}0.96 \\
0.96\end{array}$ & $\begin{array}{l}0.001 \\
0.001\end{array}$ \\
\hline $\begin{array}{l}\text { 7) Angiographic major axis (cm) } \\
\text { 8) Angiographic major axis (cm) }\end{array}$ & $\begin{array}{l}\text { Ultrasound dimension } \\
\text { Ultrasound dimension }\end{array}$ & $\begin{array}{l}\text { End-diastole } \\
\text { End-systole }\end{array}$ & $\begin{array}{l}0.98 \\
I \cdot 14\end{array}$ & $\begin{array}{l}+5 \cdot 9 \\
+4 \cdot 18\end{array}$ & $\begin{array}{l}0.60 \\
0.69\end{array}$ & $\begin{array}{l}0.01 \\
0.01\end{array}$ \\
\hline 9) Angiographic volume (ml) & Ultrasound volume (ml) & $\left.\begin{array}{l}\text { End-diastole } \\
\text { End-systole }\end{array}\right\}$ & $\mathrm{I} \cdot 02$ & $-11 \cdot 3$ & 0.91 & 0.001 \\
\hline $\begin{array}{l}\text { I0) Angiographic volume (ml) } \\
\text { II) Angiographic volume (ml) } \\
\text { I2) Angiographic ejection fraction (\%) }\end{array}$ & $\begin{array}{l}\text { Ultrasound volume (ml) } \\
\text { Ultrasound volume (ml) } \\
\text { Ultrasound ejection fraction }\end{array}$ & $\begin{array}{l}\text { End-diastole } \\
\text { End-systole } \\
\text { - }\end{array}$ & $\begin{array}{l}I \cdot 02 \\
I \cdot 01 \\
I \cdot 09\end{array}$ & $\begin{array}{r}-1 \cdot 3 \\
-20 \cdot 2 \\
+1 \cdot 6\end{array}$ & $\begin{array}{l}0.89 \\
0.90 \\
0.76\end{array}$ & $\begin{array}{l}0.001 \\
0.001 \\
0.001\end{array}$ \\
\hline
\end{tabular}

$y=a x+b ; r=$ correlation coefficient.

all records, assuming a velocity of sound of $1550 \mathrm{~m} / \mathrm{sec}$. A second record of the ventricular dimension was made in each patient at the same examination after removal of the transducer and reidentification of the septal and posterior wall echoes (Fig. I).

\section{Statistical methods}

In the group of 50 patients, linear regression was performed, by the method of least squares, between angiographic major and minor axes between each of these and echocardiographic dimension, and between angiographic and echocardiographic determinations of volume and ejection fraction. The results are given in Table 2, together with the slopes and intercepts of the appropriate regression equations, the correlation coefficients, and the probabilities that each of these differed from zero.

In the subgroup of 32 patients, in whom duplicate determinations by both methods were available, the relation between echocardiographic dimension and angiographic mean minor axis was studied in more detail. Repetitions were used to estimate experimental error and lack of fit between various polynomial expressions. Linear regression equations were derived between mean values for the two sets of measurements at end-diastole and end-systole, and patients whose values lay outside the 99 per cent confidence limits were identified. In each case the difference between the observed value for the angiographic mean minor axis and the value predicted from the echocardiographic measurement was noted, and linear regression performed between these residual values from end-diastolic and end-systolic data in the same patient. Separate regression equations were also derived for the $I$ patients in atrial fibrillation and the 15 in sinus rhythm. Standard errors of the slopes and intercepts of these regression equations were calculated, and the significance of differences between them assessed using a ' $t$ ' test (Table 3). Finally, the possible significance of quadratic and cubic terms, and of lack of fit as sources of additional variance were investigated, the results being given in the analysis of variance (Table 4). Statistical methods were those of Dixon and Massey (I969).

\section{Results}

\section{Echocardiographic data}

The distance from interventricular septum to posterior wall measured by echocardiography was between 4.5 and $8.6 \mathrm{~cm}$ (mean 6.4, standard deviation $I \cdot I \mathrm{~cm}$ ) at end-diastole, and between 3.5 and $7.7 \mathrm{~cm}$ (mean 5.2 , standard deviation $\mathrm{I} \cdot 2 \mathrm{~cm}$ ) at end-systole. The corresponding values of left ventricular volume calculated as the cube of the internal dimension were $91-680 \mathrm{ml}$ at end-diastole (mean 282 , standard deviation $154 \mathrm{ml}$ ) and at end-systole, $39-460 \mathrm{ml}$ (mean I56, standard deviation $109 \mathrm{ml}$ ).

\section{Angiographic data}

Left ventricular volume, calculated by the method of Arvidsson, was in the range 68-900 $\mathrm{ml}$ (mean 286, standard deviation $177 \mathrm{ml}$ ) at end-diastole, and $15-$ $710 \mathrm{ml}$ (mean 156, standard deviation ro9 $\mathrm{ml}$ ) at end-systole. The major axis of the ellipsoid correlated with both minor axes at end-diastole and endsystole (Table 2: $1,2,3,4$ ), while the 2 minor axes were similar in magnitude. Angiographic volume could be accurately predicted from the cube of the mean minor axis (Table 2: 5, 6). 
TABLE 3 Summary of data from 32 patients

\begin{tabular}{llllll}
\hline Dependent variable & Independent variable & Time & Rhythm & Slope & Intercept (cm) \\
\hline I) Ultrasound dimension & Angiographic mean minor axis & End-diastole & Whole group & 0.49 & 3.3 \\
2) Ultrasound dimension & Angiographic mean minor axis & End-systole & Whole group & 0.53 & $\mathbf{2 . 6 2}$ \\
3) Ultrasound dimension & Angiographic mean minor axis & End-diastole & Atrial fibrillation & 0.36 & 3.92 \\
4) Ultrasound dimension & Angiographic mean minor axis & End-diastole & Sinus rhythm & 0.53 & 2.97 \\
5) Ultrasound dimension & Angiographic mean minor axis & End-systole & Atrial fibrillation & 0.50 & $\mathbf{2 . 8 1}$ \\
6) Ultrasound dimension & Angiographic mean minor axis & End-diastole & Sinus rhythm & 0.59 & $\mathbf{2 . 2 4}$ \\
7) End-diastole residual & End-systole residual & - & Whole group & 0.59 & 0.05
\end{tabular}

\section{Comparison of volume determinations}

Comparison of estimates of left ventricular volume derived from angiography and from the cube of the internal dimension, measured by echocardiography, showed close correlation at end-diastole and at endsystole (Table 2: IO, II), the overall correlation coefficient being 0.91 (Table $2: 9$ ) and the standard error of the estimate, 6r ml (Fig. 2).

\section{Reproducibility of measurements}

Reproducibility was assessed as the root mean square of the difference between duplicate determinations. For the echocardiographic dimension, this was $3.5 \mathrm{~mm}$, and for volume was $38 \mathrm{ml}$. The corresponding figures for angiography were $6.5 \mathrm{~mm}$ and $35 \mathrm{ml}$. The latter figures might be expected to include error due to failure to expose films exactly at end-diastole and end-systole, the effects of beatto-beat variation in atrial fibrillation, and errors in measurement. There were no consistent differences between the first and second cardiac cycles studied attributable to the effects of contrast medium on left ventricular function (Brown et al., 1965; Carleton, 197r).

\section{Comparison of echocardiographic dimension and mean minor angiographic axis}

The results of linear regression between the echocardiographic dimension and the mean minor angiographic axis are given in Table $3(1,2)$. At both enddiastole and end-systole, the slope of the regression line was significantly different from I $(P<0.001)$, and the intercept significantly different from zero $(P<0.001)$. Values of 7 patients lay outside the 99 per cent prediction limits $(3 \mathrm{~mm})$ at end-diastole, 2 of whom had hypertrophic cardiomyopathy, 2 a left ventricular aneurysm, and 3 mitral stenosis (Fig. 3). At end-systole, 2 patients lay outside the 99 per cent prediction limits of $2.5 \mathrm{~mm}$, I with mitral stenosis and I with aortic regurgitation. Comparison of the overall regression equations at end-diastole and end-systole showed that the intercepts were significantly different $\left(t_{64}=3.16, P<0.01\right)$, but the slopes were not $\left(t_{64}=r \cdot 42\right)$. Comparison of residual values

TABLE 4 Analysis of variance

\begin{tabular}{|c|c|c|c|c|}
\hline Source of variance & $\begin{array}{l}\text { Sum of } \\
\text { squares }\end{array}$ & $\begin{array}{l}\text { Degrees of } \\
\text { freedom }\end{array}$ & $\begin{array}{l}\text { Mean } \\
\text { square }\end{array}$ & $\begin{array}{l}F \text { ratio to } \\
\text { error }\end{array}$ \\
\hline $\begin{array}{l}\text { End-diastolic data } \\
\text { Linear regression } \\
\text { Quadratic regression adjusted for linear } \\
\text { Cubic regression adjusted for linear and quadratic } \\
\text { Lack of fit } \\
\text { Error }\end{array}$ & $\begin{array}{r}2693 \cdot 260 \\
0 \cdot 886 \\
3 \cdot 038 \\
9 \cdot 25 \\
1 \cdot 31\end{array}$ & $\begin{array}{r}2 \\
1 \\
1 \\
28 \\
32\end{array}$ & $\begin{array}{l}1346.6 \\
0.886 \\
3.04 \\
0.33 \\
0.0409\end{array}$ & $\begin{array}{l}33,000^{\star \star \star} \\
21 \cdot 66^{\star \star \star} \\
74 \cdot 33^{\star \star \star} \\
8 \cdot 07^{\star \star \star}\end{array}$ \\
\hline $\begin{array}{l}\text { End-systolic data } \\
\text { Linear regression } \\
\text { Quadratic regression adjusted for linear } \\
\text { Cubic regression adjusted for linear and quadratic } \\
\text { Lack of fit } \\
\text { Error }\end{array}$ & $\begin{array}{l}1805 \cdot 481 \\
0.0038 \\
0.3858 \\
14.0294 \\
1 \cdot 96\end{array}$ & $\begin{array}{r}2 \\
1 \\
1 \\
28 \\
32\end{array}$ & $\begin{array}{l}902 \cdot 7 \\
0.0038 \\
0.3858 \\
0.50105 \\
0.06125\end{array}$ & $\begin{array}{c}15,000^{\star \star \star} \\
0.62 \\
6 \cdot 3^{\star} \\
8 \cdot 18^{\star \star \star}\end{array}$ \\
\hline
\end{tabular}

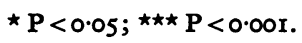


in the same patient between observed and predicted dimensions at end-diastole and end-systole, showed a significant relation between the two (Table 3) $r=0.58, P<0.001$ ) demonstrating that departure from the regression line tended to remain constant throughout the cardiac cycle. Separate regression equations were calculated for the 17 patients in atrial fibrillation (Table $3: 3,5$ ) and the 15 patients in sinus rhythm (Table $3: 4,6$ ), and comparison showed that both slopes $\left(t_{32}=3.35, P<0.01\right)$ and intercepts $\left(t_{32}=2.95, P<0.01\right)$ were significantly different at end-diastole.

The results of testing for fits of quadratic and cubic regressions on end-diastolic and end-systolic data are given in the analysis of variance (Table 4). At end-diastole, both quadratic and cubic regressions gave highly significant fits $(P<0.001)$, while at end-systole, only the cubic term was significant $(P<0.05)$. In both, lack of fit between the two methods remained a highly significant source of variance compared with random error $(P<0.001)$.

\section{Discussion}

The angiographic data in the present study confirm that left ventricular cavity shape was relatively uniform, the two semiminor axes being similar to one another in magnitude, and each bearing a predictable relation to the major axis. As the volume increased, the ratio of major to minor axis was reduced, so that the cavity became more spherical in shape. The cube of the mean minor axis was closely related to left ventricular volume, though the slope of the regression line was less than one owing to the tendency of the axes to approach one another in magnitude when cavity size was large.

It was not possible to determine the exact site of origin of the two echoes from which ventricular dimension was measured with respect to the angiogram, but from the transducer position it appeared to be just below the mitral valve. Since satisfactory echoes are only recorded when the ultrasound beam strikes a surface at right angles (Wells, 1969) a record showing interventricular septum and posterior wall simultaneously must originate in a region where the two are parallel to one another. If the left ventricular cavity were indeed an ellipsoid, as is assumed in the calculation of ventricular volume by angiography, the ultrasound beam would only have struck the septum and posterior wall at right angles had it passed along a minor axis, while if cavity shape departed from this idealized geometry, simple equivalence between minor axis and echocardiographic dimension would be replaced by a more complex calibration curve. For this reason, the relation between the two measures was studied in detail, having first established the reproducibility of each in order to separate the effects of random error from those of lack of fit. Reproducibility was estimated from duplicate determinations made under conditions where the chances of real changes occurring in left ventricular volume were small. Pairs of angiographic measurements were therefore obtained from successive cardiac cycles, while pairs of echocardiographic records were made at the same examination, separated only by the time interval necessary to remove the transducer, and to relocate the landmarks.

Direct comparison between the echocardiographic and angiographic measures showed that they were not identical, since the regression equation linking them had a slope that differed significantly from one and an intercept that differed significantly from zero. Further evidence that the calibration curve relating the two measures was not a simple one were the significant fits obtained on quadratic and cubic regressions for end-diastolic data, and that even when these more complex equations were used, lack of fit between the two methods remained a significant source of variance compared with random error, suggesting that some other variable was involved in the prediction of angiographic minor axis from echocardiographic dimension. Several factors might have contributed to this. By convention, all angiographic measurements were made from the midpoint of the trabecular system, while the main endocardial echo, arising from surfaces perpendicular to the ultrasound beam, would be expected to have arisen from its outer limit. A second factor might have been consistent underestimation of end-systolic dimensions by angiography, as demonstrated by Mitchell (1972) in the dog. Measurements by the two methods were not made simultaneously, so that any alteration in left ventricular volume caused by changes in position, heart rate, or sympathetic tone between determinations would appear as lack of fit in the statistical analysis. However, when the patients whose values lay outside the 99 per cent prediction limits were identified, they were found to include a very high incidence of those with conditions known to be associated with irregular cavity shape; mitral stenosis (Heller and Carleton, 1970), hypertrophic cardiomyopathy, and left ventricular aneurysm. Further evidence for left ventricular shape as an additional factor in determining the relation between angiographic and echocardiographic measurements were the differences between the regression equations derived from end-systolic and end-diastolic data, reflecting the striking difference in cavity shape that occurs with left ventricular contraction (Ross et al., 1967). Differences between the groups in sinus 
rhythm and atrial fibrillation might have been due to beat-to-beat variation in $R R$ interval, or have reflected the high incidence of atrial fibrillation in patients with rheumatic mitral valve disease.

If lack of fit is an important source of variance, then agreement between the two methods is likely to be better for observations made under different circumstances in the same patient, than for observations made in different patients. This was confirmed by the significant relation between end-diastolic and end-systolic residuals showing that if, in any patient, end-diastolic measurements departed from the overall regression line, then the end-systolic ones were likely to differ in the same direction by a similar amount. This suggests that values of stroke volume derived by echocardiography will be less affected by abnormalities of left ventricular shape than single estimates of end-diastolic or end-systolic volume, and also that the method may have particular value in studies of the effects of drugs or other interventions, involving multiple observations in the same patient.

In the present group of patients, the pattern of ventricular movement was normal, i.e. there was a dominant anterior movement of the left ventricular wall, and a posterior movement of the septum during ejection. After myocardial infarction localized abnormalities of posterior wall movement have been demonstrated (Inoue et al., 1971), while septal motion may be parallel to that of the posterior wall in atrial septal defect and tricuspid regurgitation (Diamond et al., 197I) in the presence of left bundle-branch block, a mitral Starr valve, or after septal infarction (unpublished observations). Under these conditions, the echocardiographic dimension may not bear a fixed relation to left ventricular volume or its reduction during ventricular ejection to stroke volume, so that these estimates should be interpreted with caution until the method has been substantiated in patients with abnormal wall movements.

I am grateful to Dr. I. Berenblut and Mr. G. Webb of the City University for assistance with statistical analysis, and to Dr. John Hamer for encouragement.

\section{References}

Arvidsson, H. (I96I). Angiocardiographic determination of left ventricular volume. Acta Radiologica, 56, 321.

Brown, R., Rahimtoola, S. H., Davis, G. D., and Swan, H. J. C. (1965). The effect of angiocardiographic contrast medium on circulatory dynamics in man. Cardiac output during angiocardiography. Circulation, 31, 234.

Carleton, R. A. (197I). Change in left ventricular volume during angiocardiography. American fournal of Cardiology, 27, 460 .

Chapelle, M., and Mensch, B. (1969). Étude des variations du diamètre ventriculaire gauche chez l'homme par échocardiographie transthoracique. Archives des Maladies $d u$ Coeur et des Vaisseaux, 62, I505.

Diamond, M. A., Dillon, J. C., Haine, C. L., Chang, S., and Feigenbaum, H. (197I). Echocardiographic features of atrial septal defect. Circulation, 43, 129.

Dixon, W. J., and Massey, F. J., Jr. (I969). Introduction to Statistical Analysis. McGraw Hill, New York.

Feigenbaum, H., Wolfe, S. B., Popp, R. L., Haine, C. L., and Dodge, H. T. (1969). Correlation of ultrasound with angiocardiography in measuring left ventricular diastolic volume (abstract). American fournal of Cardiology, 23, II I.

Fleming, J. S., and Watson, B. W. (1967). Exposure marker for angiography. British Medical fournal, 1, 742.

Fortuin, N. J., Sherman, M. E., Hood, W. P., Jr. and Craige, E. (1970). Evaluation of left ventricular function by echocardiography (abstract). Circulation, 42, Suppl. III, 120.

Heller, S. J., and Carleton, R. A. (1970). Abnormal left ventricular contraction in patients with mitral stenosis. Circulation, 42, 1099.

Inoue, K., Smulyan, H., Mookherjee, S., and Eich, R. H. (197I). Ultrasonic measurement of left ventricular wall motion in acute myocardial infarction. Circulation, $43,778$.

Mitchell, J. H. (1972). Measurement of heart volumes in man (published by title only). In Symposium on ventricular contractility. Proceedings of the Royal Society of Medicine, $65,552$.

Pombo, J. F., Troy, B. L., and Russell, J. O., Jr. (1971). Left ventricular volumes and ejection fraction by echocardiography. Circulation, 43,480 .

Popp, R. L., and Harrison, D. C. (1970). Ultrasonic cardiac echography for determining stroke volume and valvular regurgitation. Circulation, 41, 493.

Ross, J., Jr., Sonnenblick, E. H., Covell, J. W., Kaiser, G. A., and Spiro, D. (1967). The architecture of the heart in systole and diastole: technique of rapid fixation and analysis of left ventricular geometry. Circulation Research, 21, 409.

Wells, P. N. T. (1969). Physical Principles of Ultrasound Diagnosis. Academic Press, London and New York.

Requests for reprints to Dr. D. G. Gibson, Brompton Hospital, Fulham Road, London $\mathrm{SW}_{3} 6 \mathrm{HP}$. 